\title{
"Honourable Bigotry"? Relevance Theory, Conversation Analysis and Radio Talk-Backs
}

Stephen Pattemore

swpattemore@ihug.co.nz

\begin{abstract}
Relevance Theory (RT) and Conversation Analysis (CA), two disciplines with a shared interest in the pragmatics of conversation, have interacted very little. This essay shows that they have much in common in their understanding of the nature of context and its progressive construction through a conversation, and should thus be able to benefit from each other's insights into the process of communication. By means of examining the transcript of a broadcast radio-talk back conversation, two points are established. Firstly, CA can helpfully apply insights from RT to its treatment of the cooperative construction of meaning in conversation. And secondly, application of RT does not need to be restricted to fragments of invented conversation but can profitably be extended to the more complex situations of actual language in use.
\end{abstract}

"...all men feel an habitual gratitude, and something of an honourable bigotry for the objects which have long continued to please them: we not only wish to be pleased, but to be pleased in that particular way in which we have become accustomed to be pleased".

(Wordsworth, 1992: 170)

Wordsworth's description of aesthetic conservatism, at once respectable and reactionary, has been applied by Ian McKenzie (2002: 11-15) to the relationship between two types of readers of literature, the classical and the romantic. The former work with the conviction that language can be understood and that texts are the products of their author's intentions. For the latter, language itself is autonymous, opaque and intrinsically unstable. McKenzie's interest is to argue that Relevance Theory, a pragmatic (and hence "classical") account of 
human communication and cognition, offers a better framework for understanding literature than does the deconstructive ("romantic") theory of Paul de Man. It is with a degree of gentle irony then, that this essay sets out to ask whether Wordsworth's "honourable bigotry", thought of more in terms of methodological rather than aesthetic conservatism, can equally characterize the relationship between two ways of studying human communication both of which are strongly pragmatic and hence interested in language as it operates in human interaction. ${ }^{1}$

The basic datum which gives rise to this question is the almost total absence in the literature of Conversation Analysis of reference to Sperber and Wilson's (1986, 1995) Relevance Theory (RT) or any of its applications. Sperber and Wilson's (1987) "Précis of Relevance" in 1987 was accompanied by an Open Peer Commentary in which responses, criticisms and support for the theory was collected, with contributions from grammarians, semanticists, pragmatists, psychologists, sociologists, literary critics and computer scientists. But none of the names prominent in CA studies appear, nor is their perspective reflected in any of the contributions. And from the other side, while RT has been applied, since its initial appearance in 1986, to numerous and varied fields of linguistic and paralinguistic study, the area of interactional sociolinguistics, which has so profitably employed Conversation Analysis as a technique, has scarcely been touched. The conceptual closeness of these two disciplines may be illustrated by the fact that their descriptions occupy adjacent pages in Jaworski and Coupland's (1999) introduction to their Discourse Reader. Yet this possibly accidental juxtaposition is itself almost the closest point of approach.

Sperber and Wilson (1997) respond to the criticism that RT has not engaged with the social sciences with both reason and counterexample. Thus they assert that there is no systematic bias in RT's apparent ignorance of sociological consideration, merely a temporal priority of effort to first explain the psychological processes involved in communication before broadening the scope. And they provide evidence of RT-based work in a number of social science areas. But their response to methodological criticism is even more relevant to our focal question. To the criticism that RT, by attending to the microprocesses of communication, has abstracted away the real complexity of socially situated language, they contend that abstraction is always a necessity in the analysis of scientific data, and is equally performed by all social scientists, albeit at different levels. They admit that RT illustrates its arguments with (usually short) concocted examples of human conversation rather than extended transcriptions of actual interaction, thus ignoring significant features of the transactions. But again, this abstraction, they argue is only a question of scale. Transcriptions of audio-recording also systematically ignore visual and contextual elements of the context:

The real issue is not whether it is acceptable to abstract away from some aspects of reality, even though they play some role in the phenomenon studied. Everybody has to do that. Nor is there any serious argument to show that less abstraction is always better. Good abstractions contribute to relevance, and that is what makes them good abstractions(Sperber and Wilson, 1999). 
From the other side of the divide again, database and web-based searches have uncovered only one paper which in which a CA practicioner explicitly interacts with RT, and in doing so explicates the attitude communicated by the silence of other CA researchers . Milroy (2000:191) recognises the contributions of RT to the understanding of cognitive communication processes but argues that CA's strength is its "resistance to prior categorization and theorization" ${ }^{2}$ Thus although participants in conversations may orient to the Principle of Relevance, RT is weakened because it idealises conversational contributions and takes no notice of "the detritus of discourse: filled and unfilled pauses, items such as oh, yeah, mmhm". Further, according to Milroy, RT is unable to handle the collaborative construction of meaning through interaction and repair (Milroy, 2000: 205206). It must be said, however, that Milroy has merely asserted this, and has not demonstrated how RT might attempt to address real conversations, where meaning is being collaboratively constructed, and fail. Neither has any RT practicioner presented extended conversational transcripts and applied the principles of relevance to them. There does appear to be a significant gap, at least of attitude, between the two disciplines.

The gap is nevertheless surprising because RT and CA share a number of key interests, two of which we will address in this essay. The first of these is general and has to do with the nature of language and its relationship to the producers of language. The second relates more specifically to the context of communication, a central concern for all pragmatic theories. RT and CA conceive of context in ways which have more in common than in contrast. In this essay we will identify areas of convergence and divergence, particularly with respect to the concept of context. We will then examine some data, of the sort which has been of interest to CA practitioners, to see if RT has any supporting or complementary insights to offer. This will lead to a tentative answer to the question: why have RT and CA interacted so little?

\section{The context of pragmatics}

RT rejects the code model of communication as inadequate, because there is a radical gap between the propositions communicated and the linguistic forms used to do this (Sperber and Wilson, 1986: 27). This gap is filled by an inferential process, the search for optimal relevance.

A coding-decoding mechanism, left to operate unhindered and in a vacuum, would create a copy of the communicator's meaning in the recipient's mind. The sociologically crucial fact that contents get transformed, distorted, lost or suppressed in most social communication cannot be explained in terms of such a basic mechanism...[By] contrast, if human communication is of the inferential type, it presupposes and exploits an awareness of self and others. Inferential communication is intrinsically social, not just because it is a form of interaction, but also, less trivially, because it exploits and enlarges the scope of basic forms of social cognition. Right or wrong, this is a strong sociological claim (Sperber and Wilson, 1999). 
In RT, an act of ostensive communication (one which draws attention to its own communicative intent) is assumed by the hearer to be optimally relevant. From the hearer's side decoding of the surface form is followed (logically, if not temporally) by disambiguation and enrichment of the content of semantically vague elements, and interpretation of the communication takes place within a context which provides the best cognitive results for acceptable processing effort.

There are a number of strong similarities here with the approach to language exemplified by CA. Actual language use is not merely faulty instantiation of an underlying tidy and tight linguistic structure (Hutchby and Wooffitt, 1998: 5, 13-23; Drew and Heritage, 1992: 6-7). It possesses its own order and is successfully used by conversational participants to achieve their ends. Thus CA attends to the actual records of language in its sociological contexts. Once again, real language use is not explicaple in terms of decoding. Rather, the forms used draw their meaning-in-use from sociocultural context. In both RT and CA, then, language is not an autonomous code but a tool of communication, and the structure of the verbal signs is only a starting point for the work of understanding. And in both, language use is situated in context. But the similarity in this area goes deeper and deserves further attention.

\section{The pragmatics of context}

The significant and specific convergences between CA and RT treatments of context can be demonstrated from the literature in each discipline. We will first examine context in CA, and in particular in the field of institutional language. We will then describe RT's particular contributions and note the similarities between the two.

CA rejects the idea that context is a prior given situation which both contains and determines the specific instances of language use:

CA takes issue with the standard sociolinguistic notion that there is an intrinsic and causal relationship between language and the social contexts in which it is produced. Again, rather than assuming such a relationship exists, CA demands that the relevance of sociolinguistic variable for the participants themselves must be demonstrated on the basis of the data. This does not mean that variable such as gender, class or authority are irrelevant; but it does require the analyst to pay close attention to empirical phenomena and to begin from the assumption that participants are active, knowledgeable agents, rather than simply the bearers of extrinsic, constraining structures(Hutchby and Wooffitt, 1999: 5).

Rather, features of the specific language tokens used (on any level of analysis: phonological, prosodic, lexical, syntactic or sociolinguistic) provide contextualization cues, leading the hearer to interpret the utterance with reference to elements of context which are relevant. "By signalling interpretively significant aspects of the social context, they enable interactants to make inferences about one another's communicative intentions and goals" (Drew and Heritage, 1992: 8). Thus CA rejects both the extractive "null- 
context" approach of Speech Act theory, with its focus on "idealized sentences" and the more constructive but still inadequate concept of context as containing an interaction, assumed by discourse analysts of the Birmingham school (Drew and Heritage, 1992: 12-16).

Rather than seeing context as a stage set, a static platform on which the play of communication takes place, $\mathrm{CA}$ views it as a dynamic, constantly changing environment. Utterances are shaped by context but immediately shape the context of every subsequent utterance. They are both context shaped and context renewing (Drew and Heritage, 1992: 18-19). Further, not everything which might be construed as "context" is in fact relevant to a particular interaction. It is especially noticeable in institutional contexts, but nevertheless also true in ordinary conversation, that participants "orient to" certain elements of the context and not to others (Hutchby and Wooffitt, 1999:146-149). And this orienting to elements of context is itself displayed in their linguistic behaviour.

As in mundane conversation, CA looks for a proof procedure which will show how particpants make available for each other (and hence for the analyst too) the relevance of an institutional setting. That proof procedure is found in the observable details of talk-in-interaction (Hutchby and Wooffitt, 1999: 148).

Similarly, Schegloff (1992: 109) insists that the relevance of context must be demonstrated. Referring to professional encounters he proposes "that professional characterizations of the participants be grounded in aspects of what is going on that are demonstrably relevant to the participants, and at that moment - at the moment that whatever we are trying to provide an account of occurs". This leads to a yet more rigorous demand, that "procedural consequentiality" of the context, the precise way in which the element of context produces consequences in the ongoing interaction.

When a forumulation of the context is proposed, it tends ipso facto to be taken as somehow relevant and consequential for what occurs in the context. Yet it is nonetheless the analysts's responsibility either to deliver analytic specifics of that consequentiality or to abjure that characterization of the context (Schegloff, 1992: 111-112)

Context in Relevance Theory is an explicitly cognitive construction. In characterising what it is that speakers and hearers share, Sperber and Wilson reject ideas of "mutual knowledge" and "shared knowledge" as either empirically or conceptually deficient, and instead fix on the concept of manifestness and use it to define a cognitive environment:

A fact is manifest to an individual at a given time if and only if he is capable at that time of representing it mentally and accepting its representation as true or probably true...A cognitive environment of an individual is a set of facts that are manifest to him... Which assumptions are more manifest to an individual during a given period or at a given moment is again a function of his physical environment on the one hand and his cognitive abilities on the other (Sperber and Wilson, 1986: 39). ${ }^{3}$ 
Two or more people can share a cognitive environment. This does not imply that they make the same assumptions but that they are capable of doing so. This leads to the idea of a mutual cognitive environment -one in which it is manifest which people share it. "In a mutual cognitive environment every manifest assumption is ...mutually manifest" (42). This concept is considerably weaker than "mutual knowledge" and in addition cannot guarantee that communicator and audience will make a symmetrical choice of context and code to use in a communication situation. But Sperber and Wilson assert that this asymmetry is inherent in communication anyway:

It is left to the communicator to make correct assumptions about the codes and contextual information that the audience will have accessible and be likely to use in the comprehension process. The responsibility for avoiding misunderstandings also lies with the speaker, so that all the hearer has to do is go ahead and use whatever code and contextual information come most readily to hand (p. 43).

On this basis, communication is seen as the attempt to change the cognitive environment of another person, and thus to enlarge the scope of what is mutually manifest to both communicator and audience. But it is both theoretically and empirically nonsense to imagine that an audience will explore and classify all the possible contextual implications of a given utterance. Clearly there is a selecting and limiting process. Information which has no connection with the existing cognitive environment (i.e. is totally new) will have no contextual implications (though it may have its own logical implications). Conversely, information that already exists in the audience's cognitive environment will not add anything. It is information that is new but has connections with the existing environment which will have the greatest contextual effects (including negating, strengthening, extending or enriching existing assumptions). This is relevant information in Sperber and Wilson's terminology. And the relevance of information is quantified, at least in a comparative way, by extent conditions:

Extent condition 1: an assumption is relevant in a context to the extent that its contextual effects in this context are large.

Extent condition 2: an assumption is relevant in a context to the extent that the effort required to process it in this context is small (p. 125).

These two conditions illustrate the fundamental insight of Relevance Theory-that human cognition takes place in a balancing act between processing effort and contextual effect. Communication works because the audience makes the assumption that the communicator intends to communicate and intends to be relevant. But how does the audience determine the context within which to process a communication? Sperber and Wilson reject the idea that the context is determined in advance of the communication itself and suggest that the choice of an appropriate context is ongoing through the communication process and 
governed by the search for relevance:

...there is nothing in the nature of a context, or of comprehension, which excludes the possibility that context formation is open to choices and revisions throughout the comprehension process.

The immediately given context of an utterance ...is only an initial context which can be extended in different directions:

(1) short term memory of previous parts of the conversation (indicated by anaphoric pronouns)

(2) encyclopaedic entries

(3) environmental factors (indicated by deictic pronouns)

These factors determine not a single context but a range of possible contexts. What determines the selection of a particular context ... is...the search for relevance (p. 137-141).

Thus in understanding a communication, the audience does not take a particular context as given and proceed to assess the relevance of the communication. In reality relevance is taken as given and a context selected to justify that assumption.

The search for relevance by a trade-off between contextual effects and processing effort can also explain the way in which stylistic features of the propositional form of an utterance affect the meaning. Sperber and Wilson examine such features as word order and placement of focal stress, backgrounding and foregrounding, and such structural features as topiccomment, given-new and focus-presupposition distinctions. They conclude:

Given that utterances have constituent structure, internal order and focal stress, and given that they are processed over time, the most cost-efficient way of exploiting these structural features will give rise to a variety of pragmatic effects. There is a natural linkage between linguistic structure and pragmatic interpretation, and no need for any special pragmatic conventions or interpretation rules: the speaker merely adapts her utterance to the way the hearer is going to process it anyhow, given the existing structural and temporal constraints (p. 217).

The aim of communication in general is to increase the mutuality of cognitive environments rather than guarantee an impossible duplication of thoughts (p. 199-200). Where traditional discourse analysis struggles both to define context in a rigorous way and to limit its apparent endless expansion, the RT is able to define it as a cognitive, dynamic construct, and to limit the context which is applicable to the understanding of utterances by applying the criterion of relevance. ${ }^{4}$ Blass (1990) has developed the early work in this area of Blakemore (1988), and her conclusions can be summarized as follows:

(1) Context is neither simply the "context of situation" (a vague and ill-defined notion) nor simply the co-text, but the sets of mental representations (including mental representations of situation and co-text) which forms the cognitive environment within which a text is processed:

I am not rejecting the view that physical, social and cultural factors play a major role in utterance interpretation. Of course they do. I am claiming, however, that they affect 
interpretation by affecting the individual's assumptions about the world. Physical, social and cultural assumptions are just some of the many types of assumptions of which the context for utterance interpretation is composed (Blass, 1990: 31).

(2) This cognitive environment is not pre-selected or given, but is constructed in the course of the hermeneutic process in order to maximize relevance:

As a discourse proceeds, the hearer works out the contextual effect of the newly presented information in a context retrieved or derived from memory and perception. These contextual effects and new assumptions then become part of the context in which later stretches of the discourse are processed. Selection of a context will be affected by the twin aims of minimizing processing effort and maximizing contextual effect (Blass, 1990: 53).

(3) The initial context gives access to ever widening circles of context as parts of the discourse are processed and themselves give access to further assumptions and to knowledge derived from both perception and memory. This expansion of context, however, is not unrestrained but subject to the principle of relevance. Just sufficient context will be activated to obtain optimal relevance for the text being processed. This allows for the importance of co-text and yet at the same time both expands and limits the potential sources of contextual assumptions used in understanding the text.

It should be clear by this stage that CA and RT share a number of key insights into the nature of context and its applicability to utterance interpretation and the understanding of human discourse. First, context is essential for understanding human communication (both from the inside and the outside). Secondly, context is not a static, pre-determined set of circumstances or ideas, but is dynamically constructed by participants in a communication event, and constantly changing with time. Thirdly, not everything present in the environment (physical or psychological) is relevant as context, but only that which is actively accessed in the ongoing communication situation.

Relevance Theory offers, then, not only a psychological explanation for the processes of communication, but a criterion for understanding those processes, the principle of relevance, which not only governs the interactions of the participants but guides the student observing the interaction. Like CA, RT both privileges context in the search for understanding and rejects any concept of context as a static, given which somehow contains the interaction. In both disciplines it is the interaction which is the given (assumed to be optimally relevant) and context is sought, oriented-to, progressively constructed. In the last part of this essay we will attempt to apply considerations of relevance to a set of conversational data, taken from a talk-back radio conversation, to test whether there are insights to be gained from this perspective.

\section{Talk-back radio}

Talk-back radio provides interesting examples of conversation for several reasons. First, 
like all telephone conversations, the speakers are physically remote from each other and thus cannot normally rely on a common context of situation with unambiguous deictic referential possibilities. But secondly, unlike most ordinary telephone conversations, the speakers do not know each other personally. These two features combine to eliminate some of the influences of context on conversation and thus act as controls on the parameters under investigation. Thirdly, there is an institutionality and consequent asymmetry of power in the conversations (Hutchby, 1999, 1996; Hutchby and Wooffitt, 1999: 157-160, 166-169).

Some of the particular features of talk-back radio conversations which have been helpfully discussed by Ian Hutchby can be summarized as follows:

(1) Openings are different from mundane telephone conversation openings, in that the host and caller are typically already aware of each other's identity (at least by name) and thus a simple two turn sequence replaces the more normal four turn sequence in which caller and receiver establish who they are talking to. The caller to a talk-back radio show has typically already encountered one or more institutional personnel in the process of registering the call and having its purpose scrutinized. And the host's initial turn is more like an announcement to his audience than a communication with the caller. (Hutchby and Wooffitt, 1999: 157; Hutchby, 1996: 13).

(2) The caller typically introduces a topic and then takes up a position with respect to it. Topics are not usually mundane but are identified as issues about which discussion or argument can be expected. Definite articles often identify information which is assumed to be already shared. Less commonly a caller will first promote a thesis and then defend it. (Hutchby 1996: 42-48; 1999: 437).

(3) Callers are normally required to take the "first position" in an argument, a position which puts them at a disadvantage and allows the host to attack their position. If this does not happen immediately, the host will often engineer it (Hutchby, 1996: 48-50; 1999: 577-580). This is one of the principal ways in which the asymmetry of power is maintained.

(4) The agenda for discussion may be contested. This is particularly a right of the host who may challenge the validity of the caller's agenda openly, or may more subtly restate or formulate the caller's position to direct the discussion in the direction that he (the host) wants (Hutchby 1996: 55; 1999: 580-583).

(5) The host can disagree with the caller's position using one of several strategies, such as mitigated ("Yes, but...) or aggravated (No, you're wrong...) forms or by shifting his footing to present an argument as though it belongs to someone else (Hutchby, 1996: 32-36).

(6) The caller is not without resources and may attempt to turn the tables, to get the host to take up a position which the caller can then criticize (Hutchby, 1996: 55-57; 1999: 583-585).

(7) Calls are usually closed by the host, either cooperatively or confrontationally. The host may allow the caller the last word, or may produce an irenic or agreeing last turn 
himself. On the other hand the host may use his power as controller of the "switch" to cut off the caller or to have the final word himself, in which the caller's position is dismissed (Hutchby, 1996: 94-108).

\section{4. "The Mark of the Beast"}

With these findings from a CA perspective in mind we will examine the text of a telephone call to a New Zealand radio station to see if Relevance Theory can explain or add anything to deductions drawn in this way. The text is from the Wellington Corpus of Spoken New Zealand English. ${ }^{5}$ The host is a NZ European female, aged 45-49. The caller is only identified as male. The conversation took place on 13th August 1991.

Summary of the call

The call consists of 5 clear sections. Bracketed by an opening and a closing are three distinct phases of the call, which I will label "Game 1", "Game 2" and "Game 3: In Game $1(8-34)$ the caller ostensibly raises a question about the recently introduced "Kiwicard", a card allowing the holder to receive free or reduced-cost health care. The host, taking the question at face value, provides all the information that could be required only to realize that this is probably not the point of the call. She challenges the caller's (34) agenda and he then initiates a second phase. In Game 2 (35-47) the caller, still talking about the Kiwicard, narrows his focus to discuss its possible use as a means for government departments to access information about citizens. The host dismisses this, again providing factual information to counter it, but finally realizes that the caller's main point has still not appeared. She provides what is effectively another challenge to the agenda (47). At this point the caller initiates Game 3 (48-120) in which his main point is finally debated. This is that the Kiwicard will be the beginning of a process which leads to the "Mark of the Beast", a mark on the hand or forehead of every citizen without which they cannot buy or sell anything, a feature of a particular school of apocalyptic thought among evangelical Christians. ${ }^{6}$ This point is roundly contested by the host using several techniques before she deals a summary judgment and terminates the call. I have labelled the three principal phases "Games" because there is clearly a degree of gamesmanship going on in this call, and the caller is a skilled player. Twice he successfully lures the host out from the security of her position, by leading her to believe she is addressing the main point, and that it is a straightforward point of information or fact. Each of the first two games must thus be considered won by the caller, who has not yet stated his issue. This unusual exposure which the host has suffered perhaps explains some of the vigour and variety in the way she counters the caller once the third game, the real game, is properly engaged. Here she uses all the power of her privileged position to destabilize the caller's status. Although the caller never concedes, it could probably be said that the host wins the third game on points. Some closer attention to the detail of the conversation is called for. 


\section{Opening}

1 HOST we' re at the moment it's thirteen minutes past eleven as i' $\mathrm{m}$ sure it is at your place

2 HOST good morning

3 CALLER yes good morning sharon

4 CALLER how are you

5 HOST all right

6 HOST you?

7 CALLER oh not too bad

As expected, the host's first turn is more of an announcement to the wider audience, and neither host nor caller need to establish their identities. They do, however, exchange greetings and health enquiries. This last does not appear to be a feature of Hutchby's English data but personal experience listening to talk-back radio suggests it is the norm in NZ. Since this is initiated by the caller (4), it may part of his construction of his identity for the purposes of the call, as a reasonable, caring person. Thus the conversation that follows should be one between two people who have made contact as people and not just as proponents of ideas. At this point, other than his name, this is all the host knows of the caller, whereas the caller presumably knows considerably more, at least about the public persona, of the host. From an RT point of view, there are in fact a large number of assumptions which are manifest to both caller and host, which have the potential to form mutual cognitive environments. As members of the same $\mathrm{NZ}$ society, they are both aware of current developments in politics and government, and of recent history. Presumably at this particular time this domain includes discussion about the introduction of the Kiwicard and any debate that has taken place in the public sphere. There may even have been prior debate on the same talk-back radio channel. Which part of this large mutual cognitive environment the host will need to activate must await the caller's taking a first position.

\section{Game 1}

In the callers's opening turn, he establishes a footing for himself as a (probably selfemployed) orchardist, someone who is a member of the hard-working core of society, a responsible and reasonable person. Thus his introduction of the topic of the Kiwicard (8) is very innocuous and he appears to be about to take a position. The host's response shows she is waiting for the completion of the turn and the position of the caller (9). Instead, he asks a question (10), turning the tables on the host before discussion has even started.

8 CALLER $\mathrm{i}$ was out in the orchard a while ago and um er spraying copper kocide on our on our blueberries and um er the thought came to me about this kiwicard

9 HOST yes

10 CALLER and $i$ thought $i$ 'd ask you now is it basically a um a subsidised health card (4:00)

11 HOST YES

12 HOST it shows that you don't have to pay <, > anything or only part of the overnight in the hospital charge and sundry other medical charges 
From this point on in Game 1, the host does most of the talking (a total of 247 words to the caller's 133). She states the conditions for obtaining a Kiwicard and the benefits obtained from using it, accessing printed information she has in front of her (30). Most of the time the caller is simply providing encouragement for her to continue, with overlayed or latched "mhm" or "mm" . However on the few occasions where he does respond, it is to formulate some of the issues, to ensure that certain points are made:

13 CALLER $\mathrm{m}$-um $\mathrm{m}$-um mainly targeted to the poor and the disadvantaged $\mathrm{o}-\mathrm{o}$-obviously $=$

20 CALLER =um absolutely so the um the um er the dependants (slowly) who would (normal speed) be dependent on that er well er you know well they they wouldn't be able to afford it i guess er sh- er sharon so er the only way they could get any help is to probably [um] er collect a kiwicard (5:00)

With the benefits of seeing the entire conversation, it is clear that these comments (and in particular those in bold type) are leading in a particular direction, namely that at least certain sections of society will have no choice about how their economic affairs are arranged. But the host does not pick up on this at all, continuing to concentrate on the specific benefits and conditions of the card.

Relevance-theoretic perspectives offer some interesting insights here. Later parts of the conversation show that the host knows at least something about the "mark of the beast", the callers true issue (49), and in fact knows that this comes from the biblical book of Revlelation (119); and the host has also had a previous conversation with this same caller on this issue (104). Why, then, does she not tumble to the caller's intentions sooner? The answer probably has to do with optimal relevance and the carefully constructed nature of the caller's turns. When the caller refers to "this kiwicard" (8), he leads the host to access a cognitive environment containing all the assumptions about the Kiwicard that are in the public domain. With this context open, he asks "Is it basically a subsidised health card?" he host interprets this question in keeping with optimal relevance, as a straightforward enquiry about the nature of the Kiwicard. This interpretation is optimally relevant because the mundane vocabulary ("subsidised health card") and the common-sense adverb ("basically") mean it requires little processing effort. Knowing what she does, it would be possible for the host to interpret the question to mean "Is this a simple tool of bureaucratic health administration or is it the first stage in a process which will lead to totalitarian economic control and the "mark of the beast' as outlined in the 13th chapter of Revelation?" However this would take far more processing effort than was warranted, and so this interpretation is never made. What is more, the caller did not at this stage intend for this interpretation to be made. He phrased his question such that the optimally relevant answer would be one which highlighted the conditions for use of the card. He does this because he wants to underline a degree of inevitability or inescapability of the card (20). He also wants to keep his own agenda hidden as long as possible and gain as many concessions or statements from the host as possible before revealing it. When he makes the statement at the end of 20 , with the "so" marking a summary position which he invites the host to 
confirm, she interprets this by opting for maximal rather than optimal relevance. She has the sheet of facts in front of her and can supply any officially provided answer about the Kiwicard. The caller may not have known this. It is when she is drawn right out into the open like this that she realizes her lack of cover, and that the caller has yet to make a point, and challenges his agenda (34):

27 HOST and on it goes [um] $<$, > childless non- beneficiaries

28 CALLER [mm]

29 HOST and families ABOVE the family support abatement point

30 HOST i've got a table here

31 HOST ask me a question

32 HOST i've got the answer=

33 CALLER =ha ha that's very good well=

34 HOST so what's [your point]

\section{Game 2}

Game 2 begins with an example of optimal relevance on a micro-scale:

34 HOST so what's [your point ]

35 CALLER [the point] i'd like to raise is the fact that um um do you think the kiwicard coucould be the thin e- end of the wedge $<,>$ um in respect of um er because (6:00) they threw out a- out this i $\mathrm{d}$ card in australia ty- some type of er card er er a few er a few years ago and um $<,>$ um $<,>$ er $\mathrm{i}$ i can understand that this kiwicard would um would be a great blessing a- as far as all the er government d- er departments are concerned $=$

The caller does not need to hear the completion of the question (34) before responding in overlap with almost identical words to the host. Given the context of the discussion so far, and the fact, manifest to both parties, that the caller has not yet taken a position, a question from the host beginning "So what's.." can only have one optimally relevant conclusion and the caller anticipates it. This turn is the caller's longest turn in the entire conversation. He continues to topicalize the Kiwicard but now describes it with an idiom (or cliché) "the thin end of the wedge". This makes available several implicatures: the caller is suggesting that the Kiwicard may not be very significant in itself but it is a small beginning which will lead inevitably to something much bigger; further, that something bigger may be harmful or destructive. ${ }^{8}$ Two supporting assumptions are presented by the caller. Firstly Australia had earlier tried and abandoned an ID card. This has the implication that it was found to be unsatisfactory. But since the possibility of the abandonment of the path starting from the Kiwicard does not suit the caller's intentions this argument is not developed further anywhere. Second, the caller suggests that it would be a "great blessing" for government departments. The phrase "great blessing" is scarcely a normal part of secular vocabulary in the latter part of the twentieth century (it may be so for an older generation, but we have been led to understand that the caller is probably of working age) and should give the host 
access to the religious dimension of the caller's cognitive environment. But she does not respond to this element. Furthermore, the caller has not specified what sort of benefit the Kiwicard might be to government departments. The optimally relevant interpretation, as shown by the host's response, relates this to the accessing or sharing of personal information by government departments:

36 HOST =no because the budget allowed for government departments to $=$

37 CALLER $=$ yep $=$

38 HOST = swap information=

39 CALLER =that's [it yeah yes right]

40 HOST [so two things have have happened] the kiwicard is to show whether you're eligible for certain welfare benefits in the health area $=$

41 CALLER = right [right]

42 HOST [and] there's the other crosschecking which is called an information exchange and that allows people to get together in a $\mathrm{c}$ c inland revenue um $<,,>\mathrm{oh}=$

43 CALLER =um inland revenue um justice department [(unclear word)]

44 HOST [yes ] immigration that sort of thing [and ] and department of social welfare $=$

45 CALLER [right]

46 CALLER $=\operatorname{right}(7: 00)$

This is a typical subject for talk-back radio and the cue provided by the caller leads to it with little processing effort. The host counters the suggestion that the Kiwicard will further erode the privacy of individuals by appealing to the fact that government departments can already share all the information they need. The caller merely attends to and supports this, indicating that he is not contesting the host's statements, and therefore that this was not his point. The constant barrage of support instead of argument finally leads the host to recognise this and she closes this game with an implicit concession that she has missed the point, which at the same time challenges the caller's agenda again:

46 CALLER =right $(7: 00)$

47 HOST well you KNEW all this didn't you

\section{Game 3}

Game 3 is the longest and most complex of the three and we will not attempt to exhaust its analysis but focus on how the host deals with the issues raised by the caller. The game consists of several fairly clearly defined phases, which to pursue the tennis idiom we might label "rallies". ${ }^{9}$ The first begins (48) with the caller rather hesitantly, and with hedges, finally stating his main position, identifying the Kiwicard as the first step towards a particular form of totalitarian economic control characterised by the "mark of the beast". In doing so he refers not only to the "mark of the beast" but more generally to "Bible prophecy" and this statement makes optimally relevant a large cognitive environment containing assumptions about the nature of canonical texts (such as the Book of Revelation) and the content of those texts. 
"First rally"

48 CALLER well $\mathrm{i}$ i i i have $\mathrm{i}$ have got that yes and um but the point is this that um it's the thin en- end of the wedge in THIS respect $i$ believe sharon that um that bible prophecy is getting closer and closer as er far as the mark of beast is concerned

49 HOST on i don't think the mark of the beast is likely at the moment do you=

50 CALLER = we-=

51 HOST = the greatest beast on the planet is is is man's inhumanity to man=

52 CALLER =(laughs) so true and of course um that's how $i$ - $i$-it has all all begun hasn't it

53 HOST well $i$ don't think the kiwicard is going to be the start of the mark of the beast $i$ really don't

Although the host now holds the vantage point of "second turn", she does not use it to question the truth or relevance of this whole cognitive environment, but actually brackets these issues and responds as if she shared the basic assumptions but was questioning the detail of timing - whether in fact the "mark of the beast" is "likely at the moment" (49) and whether the Kiwicard will lead to it (53). What is particularly interesting is that, not having attempted at her first opportunity (i.e. in her "second turn", 49) to overturn the basic assumptions undergirding the cognitive environment into which the caller has led the discussion, she never overtly does so in the remainder of the conversation. Having implicitly conceded the relevance of the caller's presuppositions (though not of his assertions) she cannot regain that ground. She has, in fact, contributed to the cooperative construction of meaning. The most she can do is on several occasions to make remarks which communicate, not as explicatures but as strong implicatures, the fact that she queries the basic schema of the caller. These remarks occur at 51 (above), 91-93, and in her summarising phase (118-122) which we shall show later.

91 HOST oh god look MEN have been $<,>$ [ruining the world for centuries]

92 CALLER [(laughs)]

93 HOST the mark of the beast has nothing to do with it (10:00)

These segments convey the implicature that the responsibility for social and economic woes in the world lies with human beings rather than with some hypothetical "beast". This implicitly negates some of the assumptions the caller has made relevant. As a side-issue at this point, which is nevertheless relevant to our overall concern in this essay, Line 91 contains an ambiguity which is nicely resolved by RT's concept of context as an ongoing construction. Is the host by this remark blaming humanity in general, or male persons in particular? The prosody (emphatic "MEN") and the host's social identity as a woman lead us towards the latter interpretation. But all ambiguity is resolved when we recognise the context into which this remark falls. The initial context opened up by the caller contains the assumption that the "beast" is male, as opposed to the female "great prostitute". True, the host has referred in 51 to "man's inhumanity to man", a stock phrase which is gender inclusive and cannot be rephrased ("humanity's inhumanity to humanity"?) with any degree of elegance. But this context has already been modified only a few remarks earlier 
by the following interchange:

81 HOST why don't we just get on with our lives and wait for HIM IT <, >

82 HOST won't be a woman of course

83 CALLER oh that's that's one that's w- that's thankful for that too sharon

The host here reinforces the initial assumptions, showing them to be her own and also patently obvious. Thus line 91 must almost certainly be interpreting as referring to men as opposed to women.

Returning to our main line of investigation, it is clear in each of the "rallies" that the host, now that she has perceived the issue and position of the caller, does everything she can to keep the ball in his court and retain for herself the privilege of second turn. After the first rally, which consists of a number of long base-line shots (48-53a above), her contributions are either short ("at the net") as in the second rally ( $53 \mathrm{~b}-60$ below) or they consist of an initial "serve" which requires the caller to explicate his position in more detail, followed by briefer interruptions or responses.

\section{"Second rally"}

53 HOST well $\mathrm{i}$ don't think the kiwicard is going to be the start of the mark of the beast $\mathrm{i}$ really don't

54 HOST do you

55 CALLER w-yes ido =

56 HOST [why]

57 CALLER [I] i really do u- [um] sharon

58 HOST [i mean h-]

59 CALLER and $i$ wondered if um there's a lot of um er churches out there who may have some of the answers

60 HOST WHAT

61 CALLER and um how this um how this mark of the beast is is er beginning to take shape

\section{Examples of "serves"}

62 HOST well tell us how the mark of the beast is starting to take shape with a kiwicard that allows [people to have some help with] their $(8: 00)$ health costs $=$

70 HOST [well look let us ] short circuit this -logical this [illogical] thing and tell us what the end is

77 HOST = so if the beast is going to come to pass why ARE you worried about the kiwicard [if it is ] inevitable that

102HOST [well ] you haven't told me how it's going to take shape apart from having a credit [card]

Often the host allows the caller's previous point to stand unchallenged overtly but 
challenges the implications: "If that's so, then what about...?" This is seen in 77 above but also in the earlier lines:

74 HOST [but LISTEN you don't ] have to have a bankcard

75 HOST you can $<,>$ really stymie the beast by not having any credit cards [at all ]

Other features of this game are the increased number of interruptions and overlaps, an increased "temperature" of exchange and an increased degree of hesitation and partial word-formation on the part of the caller. This last may well be due to the fact that it is manifest to him that he is no longer in the more powerful position and knows that each statement he makes is a potential target for the host. He is also aware that his remarks are made in the spotlight of public radio and that his credibility with the audience is at stake. Combined with the fact that his position is a minority one in society at large, these assumptions lead to his greater hesitancy, embarassed laughing interruptions $(71,80,92)$ and the like. Laughter as an interruption also makes manifest to host and audience that he remains good natured and rational. The host is also very aware of the wider audience and directs some remarks to them as much as to the caller eg:

107 HOST [and who's going to do this look we've had this conversation before]

108 HOST (quietly)(this is?) pointless

\section{Ending the call}

Finally, the call is brought to a conclusion by a summary from the host in which she dismisses the caller's position as not new (118), not credible (121), irresponsible (121) and not admissible in public discussion because it represent private belief (121-122).

118 HOST people have been saying that the world will end that [doom is nigh $<,,>$ that we will be extinct and they've been saying it for centuries]

119 CALLER [i-i agree with you and it's all for nought]

120 CALLER absolutely [an-]

121 HOST [so ] what makes you any more credible really and isn't it a question of our own individual relationships with god really not something to be discussed on talkback to $(12: 00)$ put the wind up people who are already anxious $<$, $>$

122 HOST they can read revelations just as $\mathrm{i}$ am sure you have done and make their own decisions

123 CALLER yes indeed and it's certainly coming to pass though sharon $<$, $>$ [and that's (unclear word)]

124 HOST [all right well we'll w- watch] with interest

125 CALLER okay my dear

126 HOST okay [bye] bye $<$, $>$ well now $i$ think he's perhaps better off back in the orchard (12:18)

127 CALLER [bye]

Having made this strong and comprehensive dismissal, she allows the caller the luxury of 
the final word (123) which she does not challenge (124). After the closing pleasantries, she makes a remark to the audience (126 - presumably the caller has not yet switched his radio on again) which provides a neat inclusio to the caller's opening self-characterisation, effectively consigning him to his original environment out of the public arena.

\section{Conclusions: Honourable Bigotry?}

Having first examined some of the theoretical connections between Relevance Theory and Conversation Analysis, and then applied resources from both disciplines to the analysis of an example of real conversation we are in a better position to answer the question with which we began this essay. Why has there been so little interaction between these two closely-related disciplines? The results of our investigations tend to lend support to the supposition that "honourable bigotry" rather than any deeply significant principled difference is behind it.

In the first place we have seen that RT shares with CA a commitment to understanding language as it is actually used in communication, rather than in an abstract construct. And the precise nature of the context which is so critical for understanding communication (either from the inside as participants or from the outside as analysts) is understood in a very similar way in each case.

But we have further seen in practice that considerations of optimal relevance and the nature of cognitive environments have been helpful, alongside of the perspectives already established in $\mathrm{CA}$, in understanding an actual example of a conversation in the public domain. Relevance Theory claims not to be "just another" way of understanding communication but to describe the underlying cognitive processes behind all ways of understanding. As such it provides a theoretical foundation for analysis of real-life conversation. But on a more surface level, the criterion of optimal relevance also acts as a sharpened hermeneutical scalpel in dissecting the conversation. And, contrary to Milroy's assertion, it is capable of explaining both the "detritus" of conversation and the cooperative construction of meaning.

From the other side, there seems little reason for relevance theorists to continue to avoid applying the theory to the details of real conversation. Even if the explication of the theory required a level of abstraction and deliberately constructed examples, once established as a valid framework, there is nothing which prevents its being used in the analysis of conversation.

To characterize the the relationship between CA and RT as "honourable bigotry" may be ironic but it is not intended to be sarcastic or critical. There have been plausible reasons from both sides for the gap. But it is the contention of this essay that these reasons are no longer sufficient. Considerations of optimal relevance in mutual cognitive environments have the potential, taken alongside other proven techniques, to throw light on the analysis of conversational data. And relevance theorists, or those who apply their theories, can with profit turn their attention from the concocted examples necessary for the establishment of the theory, to the records of real conversation. 
Notes

1. My use of the term pragmatics follows Levinson (1983) and assumes such working concepts as "language in use", or "language in context" (Levinson, 1983: 32).

2. Since his experimental focus is on the conversational practices of aphasic subjects, it may be permitted to wonder if his conclusions are equally valid for ordinary conversation.

3. All the following page references are to Sperber and Wilson (1986) unless otherwise specified.

4. For a more detailed discussion of the ways in which RT helps overcome some of the problems facing discourse analysts, see Pattemore (2003: 45-58).

5. Wellington Corpus of Spoken New Zealand English, WSC\#DGB007. I provide in Appendix A the entire text of one call but have omitted a section of an earlier call which is part of DGB007. My transcriptions have been adapted from the format of the WSC data and transcription conventions are listed in Appendix B For details of data collection procedures and conventions see Holmes, Vine and Johnson (1998).

6. The allusion is to Revelation 13".16-17.

7. Incidentally, Milroy's criticism, that RT cannot handle features such as these in conversation, is simply not true. It may not add anything significant to the analysis, but the situation can certainly be expressed in relevance-theoretic terms. The statement "mhm" makes optimally relevant to the hearer the assumptions (1) that the listener is attending and (2) that the listener does not consider the speaker's turn to be complete yet.

8. This last is a weak implicature derived from the nature of a "wedge" and its action in a block of wood and requires extra processing, going behind the conventional meaning of the idiom to its non-idiomatic sense. Even if it is derived by the hearer, they would not be sure that it represents the speaker's intentions.

9. I identify these as composed of lines 48-53, 54-61, 62-69, 70-73, 74-76, 77-84, 85-101, 102-109, 110-117. In each case the host uses one of several strokes to put the ball in the caller's court, pushing him to take or justify a stand.

\section{References}

Blakemore, Diane (1988): "Organisation of discourse". In F.J.Newmeyer, ed., Linguistics: The Cambridge Survey, vol. 4, Language: The Socio-Cultural Context. Cambridge: Cambridge University Press: 229-250.

Blass, Regina (1990): Relevance Relations in Discourse: A Study with Special Reference to Sissala. Cambridge: Cambridge University Press.

Drew, Paul, and John Heritage (1992): "Analyzing Talk at Work: An Introduction" in Drew and Heritage (eds.) Talk at Work. Cambridge: Cambridge University Press, 3-65.

Holmes, Janet, Bernadette Vine and Gary Johnson (1998): Guide to The Wellington Corpus of Spoken New Zealand English. Wellington: School of Linguistics and Applied Language Studies, Victoria University of Wellington.

Hutchby, Ian (1996): Confrontation Talk: Arguments, Asymmetries and Power on Talk Radio. Everyday Communication: Case Studies of Behavior in Context; Mahwah, NJ: Lawrence Erlbaum. 
. (1999): "Power in Discourse: The Case of Arguments on a British Talk Radio Show" in A. Jaworski and N. Coupland, eds., The Discourse Reader. London: Routledge, 576-588. Hutchby, Ian and Robin Wooffitt (1998): Conversation Analysis: Principles, Practices and Applications. Cambridge: Polity Press.

Jaworski, Adam and Nikolas Coupland (1999): "Introduction: Perspectives on discourse analysis". in A. Jaworski and N. Coupland, eds., The Discourse Reader. London: Routledge, 1-44.

Levinson, Steven C. (1983): Pragmatics. Cambridge: Cambridge University Press.

MacKenzie, Ian (2002): Paradigms of Reading: Relevance Theory and Deconstruction. Basingstoke: Palgrave Macmillan.

Milroy, Lesley (2000): "Negotiating meanings with the least (collaborative) effort -or how conversationalists help each other along". In Michigan Discussions in Anthropology. University of Michigan, Progam in Linguistics, 190-206.

[http://www-personal.umich.edu/ jherron/public/courses/anthro531/readings/milroy _ negotiating.pdf].

Pattemore, Stephen W. (2003): Souls under the Altar: Relevance Theory and the Discourse Structure of Revelation. UBS Monograph Series 9, New York: UBS.

Schegloff, Emmanuel A. (1992): "On talk and its institutional occasions". In P. Drew and H. Heritage, eds., Talk at Work. Cambridge: Cambridge University Press, 101-134.

Sperber, Dan and Deirdre Wilson (1986): Relevance: Communication and Cognition. Oxford: Basil Blackwell, (2nd ed, 1995).

. (1987): "Précis of Relevance: Cognition and context". Behavioural and Brain Sciences 10: $697-754$.

145-151.

(1997): "Remarks on relevance theory and the social sciences". Multilingua 16:

Wellington Corpus of Spoken New Zealand English

Wordsworth, William (1992): Lyrical Ballads and Other Poems, 1797-1800. Ithaca, NY: Cornell University Press, ed. by James Butler and Karen Green. 